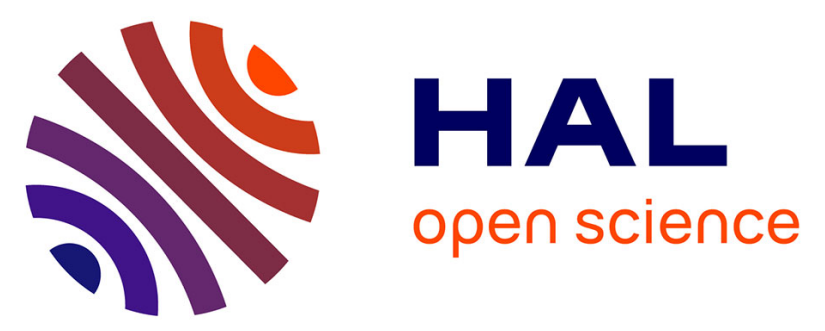

\title{
Collaborative Serious Games for Awareness on Shared Resources in Supply Chain Management
}

Jannicke Baalsrud Hauge, Matthias Kalverkamp, Margherita Forcolin, Hans Westerheim, Marco Franke, Klaus-Dieter Thoben

\section{To cite this version:}

Jannicke Baalsrud Hauge, Matthias Kalverkamp, Margherita Forcolin, Hans Westerheim, Marco Franke, et al.. Collaborative Serious Games for Awareness on Shared Resources in Supply Chain Management. IFIP International Conference on Advances in Production Management Systems (APMS), Sep 2014, Ajaccio, France. pp.491-499, 10.1007/978-3-662-44736-9_60 . hal-01387923

\section{HAL Id: hal-01387923 \\ https://inria.hal.science/hal-01387923}

Submitted on 26 Oct 2016

HAL is a multi-disciplinary open access archive for the deposit and dissemination of scientific research documents, whether they are published or not. The documents may come from teaching and research institutions in France or abroad, or from public or private research centers.
L'archive ouverte pluridisciplinaire HAL, est destinée au dépôt et à la diffusion de documents scientifiques de niveau recherche, publiés ou non, émanant des établissements d'enseignement et de recherche français ou étrangers, des laboratoires publics ou privés.

\section{(c)(1)}

Distributed under a Creative Commons Attribution| 4.0 International License 


\title{
Collaborative Serious Games for awareness on shared resources in supply chain management
}

\author{
Jannicke Baalsrud Hauge ${ }^{1}$, Matthias Kalverkamp ${ }^{2}$, Margherita Forcolin ${ }^{3}$ Hans Wes- \\ terheim ${ }^{4}$, Marco Franke ${ }^{1}$, Klaus-Dieter Thoben ${ }^{1}$ \\ ${ }^{1}$ Bremer Institut für Produktion und Logistik, Bremen, Germany \\ \{baa, tho,fma\}@biba.uni-bremen.de \\ ${ }^{2}$ Research Group Cascade Use, Carl von Ossietzky Universität Oldenburg, Germany \\ matthias.kalverkamp@uni-oldenburg.de \\ ${ }^{3}$ Cetim, Leiden, Netherlands \\ Margherita.forcolin@cetim.org \\ ${ }^{4}$ Department of Computer and Information Sciences, NTNU, Trondheim, Norway \\ hansw@idi.ntnu.no
}

\begin{abstract}
Today manufacturing is a complex process often resulting in long brittle supply chains with considerable contributions to the global resource demand also posing a negative environmental impact (CO2 emissions, raw material supply, etc.). Reducing the waste of resources and being more sustainable are objectives incentivized by materials in short supply and customer requirements. Thus, the ability to share resources, innovate and to implement emergent ICT will play a key role for companies' competitiveness and their sustainability. However, sharing resources puts high requirements on trust and gain sharing, amongst others. Although well known in supply chain management, the logistics sector is struggling to increase their shared resources. The authors found serious games (SG) to be a promising tool for awareness rising on shared resource. Existing supply chain games are analysed and their potential and weaknesses for the topic are examined, resulting in an outlook on the research needs in SGs for awareness on shared resources.
\end{abstract}

Keywords: Serious Games, Shared resources, Logistics, CPS

\section{Introduction}

Today manufacturing is often a complex process involving several partners around the world [1] and based on economy of scale principles [2]. It results in long brittle supply chains with a considerable contribution to the $\mathrm{CO}_{2}$ emissions [3]. The supply chain can be seen as an ecosystem of different actors with different needs, acting in a dynamic environment [4]. Customer response, exception management, scheduling, prediction and forecasting are some of the key factors that have to be continuously improved and monitored [5], thus, monitoring the quality of service, supply chain visibility and security have becoming major factors determining logistics processes besides e.g. costs, duration, and carbon footprint $[3,4,5]$.

The European manufacturing industry's basis is build by innovative SMEs with an excellent R\&D base that allows them to thrive on the world market. However, due to the trend toward more customized products with shorter life-cycle the marginal cost per product is increasing and low efficiency of the logistics system is a challenge to

adfa, p. 1, 2012.

(C) Springer-Verlag Berlin Heidelberg 2012 
overcome for reducing the costs and emissions. Studies reveal that the utilization of e.g. trucks on the roads vary between 30 to 50\% [7], partly caused by the reduced size of each product and more efficient packaging, but also because the transport capacity was not adjusted correspondingly [8,9]. The trend to reduce the waste of resources is not specific to the manufacturing industry, but combined with the increasing world market prices for raw materials the incentives to be as sustainable as possible are stronger. Thus, the ability to share resources, innovate and to drive the implementation and deployment of emergent ICT will play a key role for their competitiveness.

In comparison to the manufacturing area where more and more strategic partnerships are (e.g. extended/virtual enterprises) formed along the supply chain, similar concepts are hardly deployed in the logistics field, even though a better utilisation would lead to cost savings, improved environmental balance and a more sustainable business models, but it also requires trust, coordination, joint planning and problem solving [10]. Business to business (B2B) technology enables a set of complex business processes across distinct operating entities. This allows participants along the entire supply chain to share decision-making, workflow, and capabilities. Furthermore, the technology enables participants to collaboratively design, build, sell and service products faster, more efficiently, and more cost effectively on a global scale. The cooperation can be described in terms of integration within the scope of the network as well as in terms of the strength of the inter-organisational bond [11, 12]. This paper aims at identifying and analysing different barriers for an increased access to shared resource. The second part of the paper deals with potential means to reduce and overcome some of these barriers by providing teaching concepts for awareness raising of the opportunities shared resources may give.

\section{A need for a shift towards production ecosystems}

The traditional supply chain is product-centric, mostly focusing more on production cost reduction than on also including environmental and societal impacts into the optimisation strategy (i.e. using multi-criteria strategies). Consequently, for many years production was delocalized in remote low labour cost countries far from the market. This strategy worked well as long as the transport costs were low and the customer did not care so much about environmental and societal impact in the countries of production or for the environmental impact of transport.

This perception has been slightly changed, and both customers and low cost countries' governments pay more attention to the societal and environmental impacts of the transportation. In addition, most of these countries are now facing increasing wealth, and thus also increasing wages. Thus, there is a need for new production strategies and, thanks to enhancements in ICT technologies; demand driven optimization strategies have been developed [13] both considering new production possibilities (i.e. 3D printing) and local sourcing trends.

Looking ahead, these trends will enforce changes at different levels. On the supply side a market transformation is foreseeable towards more operational cooperation between the different players in the logistics field. Current resistance factors, mostly market protection and lack of trust, will have to be overcome. On the demand side, 
further globalisation, increases in product variants, personalized solutions and ecommerce might lead to a future establishment of "selling less of more" practices. For the logistics and manufacturing sectors, this will mean that environment-sensitive clients will be at the same time demanding fast and highly customised services. Both producer and the suppliers will profit from collaborative production by sharing resources and access to information through less inventory, less transport costs and improved resource utilisation as well as through a better environmental balance, but it has a negative influence on their flexibility: The requested delivery date by the customer strongly depends on the agreement with suppliers when they can deliver the needed components, which again depends on their production capacity. Sharing resources leads to less flexibility, since the access to the production means or logistics transport means is not only depending on in-house priorities but also on agreements with other collaboration partners. In addition, use of shared resources does increase the complexity of planning and reduces the freedom in the decision making process. This, in combination with the increasing pressure from customers and suppliers for transparent communication and information provision of product properties (e.g. process parameters used, components included) and related information (e.g. on-time according to plan, quality aspects), forces manufacturing companies to think of new ways to utilize the available infrastructure and intelligently add new technological applications. In order to enable innovative cost- and resource-effective product solutions, with a minimal ecological footprint throughout the lifecycle, a holistic view on the supply chain and all its stakeholders (i.e. also the LSPs, transports companies and customs etc as well as manufacturer) should be considered. The challenge of mastering the complexity of applying a shared resource concept in a supply chain context can be envisaged from Ousterhouts layered model, showing the goods and information flow as well as the interaction among stakeholders at different layers in the supply chain (fig. 1).

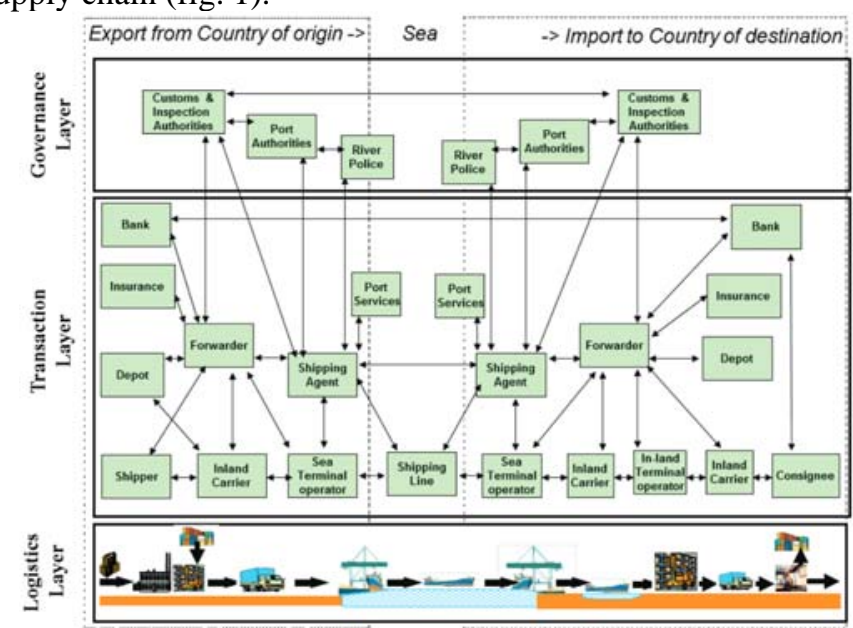

Figure 1: Oosterhouts layered Model [14]

Based on fig. 1, it appears that the shared resource approach puts several complex requirements both on the collaboration between the stakeholders as well as on the ICT 
infrastructure, and thus may be a source for the low deployment and many of the existing barriers.

\section{Challenges and barriers for improved cooperation and the access to shared resources}

The hard global competition, inter-dependencies among stakeholders, tight schedules leads to need for better utilization of available resources. The innovation in the use of shared resources consists of bringing together the resources and capabilities of different stakeholders in a supply chain (e.g. logistics services, providers and shippers) to address the optimisation and sustainability challenges faced by the logistics and transport domain. In Europe, several manufacturers, suppliers and logistics and transport service providers are micro and small enterprises. These companies possess profound, specialized competences [15], but do often face a shortage in access to resources, in terms of human resources, funding as well as complementary assets and technologies [16]. Collaboration giving access to new, shared resources will ensure a better overall utilization [17]. A better utilitsation of resources can be realized today, by adding more intelligence in the existing ICT solutions as well as by increasing the adoption and integration of on-cargo and on-vehicle technologies as well as by using existing SCM tools for planning and execution, but is scarcely adopted. Thus in order to understand the low use, a survey was carried out in order to identify barriers that can limit uptake of new ways of sharing or using innovative solutions. When analyzing the limitation regarding the sharing of information, it was clear that a main problem is the lack of trust among the stakeholders [4]. Trust between the involved organizations is however a pre-requisite and can only be achieved through long-term relationships between the actors and contracts that decrease the distance between the companies. Looking at common practice within the supply chain today, the use of short-term contracts is high. Shared resources require that more data needs to be processed and analyzed than if the resources are only used within a company, since the planning comprises not only own needs but also those of the collaborative partners. This leads the need for systems interoperability between the actors involved and a need for single, easy to use collaborative platforms, linked to the legacy systems. This becomes more important when the number of smaller-size organizations involved (e.g. such as smallholders, consumers purchasing groups, etc.) is high and when the logistics infrastructure is shared. In addition to barriers related to sharing of information at a technical level, which is a well-known barrier, and for which concepts like federated platforms etc are in place, there are also barriers related to the business models. Most innovative business models are based on the perception that collaboration can lead to better results for everyone involved. For introducing them, models of how these results are to be split will have to be put in place from an early stage Such models should lead to quantifiable results and be very clear in their use and they should allow for synergy gain calculation and redistribution. Furthermore, business models that involve the collaboration of various actors during the physical delivery process require common or compatible operational practices among the actors involved. This is a typical barrier found in most cases of horizontal or vertical coopera- 
tion in the supply chain. In addition, as mentioned above sharing resources has a direct influence on the flexibility, thus sharing infrastructure (especially physical one) among various partners requires clearly defined practices. Finally, the last area analyzed is related to organizational issues - the decision making process differs among the different stakeholders. This in turn, increases the complexity as well as the challenge to keep the decision-making process transparent (local, central, management level etc.); in addition the concept of shared resources can only be realized throughout the supply chain by implementing advances ICT. The adoption of innovative technologies implies changes in the workforce of an organization. New expertise is required while skills acquired previously may become obsolete. In emerging technologies there are few people with the necessary competences. Additionally, the adoption of innovative technologies may result in frustration to the employees that have to change the way they normally used to do their job. All in all, so far it has not been possible to measure/assess the positive effect of the shared resources concepts in across the supply chain to such an extent that it has broadly uptaken and implemented. The next section will therefore discuss approaches based on experiential learning that might be used in order to create the required understanding of advantages and limitations of shared resources.

\section{$4 \quad$ Why use serious games}

General trends supporting the use of shared resources like the Internet of Things will impact significantly on the supply chain as a whole. On the one side allowing, monitoring and handling goods through distributed computing infrastructures and, on the other side, allowing easy publication, retrieval and composition of freight information service.

A successful introduction, implementation and operation of advanced technical solutions necessary for using share resources is not only a matter of hardware and software, but it does imply changes both in the organizational structure of the stakeholders' organizations as well as in the working environment of the employees. Thus, a key to a successful implementation of shared resources concept in supply chains is to increase the awareness [18]. Due to its high motivation factor and the possibility to let the participants play an active role, the use of experiential learning forms has been increasing within education at all levels [19, 20, 21]. With SCM and OR education, serious games are regularly used to overcome the gap between theory and practices. The most famous one is still the Beer Game [23] was developed by MIT to simulate the dynamics of a supply chain explaining the bullwhip effect which has been digitalized into online gaming format and systems thinking [23]. Games focusing at different areas of SCM including manufacturing can be found in [19, 20, 21, 25, 26].

Within the vocational training, there are several examples on how SG are used in the executive training for decades as well as examples on how games can be used in the training of operational personnel $[27,28]$. Most of these games are multi-player games, not only focussing on the specific problem, but also aiming at conveying the players the importance of communication and collaboration in a supply chain context through their own experience in the gaming environment. Through such games, the 
players also experience that information sharing and trust are key factors for successful and sustainable collaboration in supply chains.

The above discussed challenges and barriers for implementing shared resources in the supply chain require knowledge and skills about the mid- and long-term impact of collaboration decisions on security, trust, operational practices and gain-share. Looking at available games used for SCM [21, 24] the collaboration and trust raising aspect is covered in several games, and games like the Fresh Connection, also take business consideration into account at a certain level. But a thorough analysis also reveals that they do not cover all barriers like the challenge visualising gain sharing models as well as how to optimise the utilisation of machine and transport capabilities by a high degree of flexibility. Depending on how games like Shortfall and the Lean Leap Logistics Games, the Beer game [25, 26] are embedded in a learning unit, these games can be used to discuss and make the players aware and able to understand how these barriers are related, but their simulation models does not mirror the complexity well enough for the topic of shared resources and therefore need to be extended in order to fully cover the complexity. Still unsolved is the question on how to develop simulation models mirroring the reality of the complex interaction better, and thus able to demonstrate the challenges of ownership of a shared resource etc. (what happens if a partner needs access to a shared resource while it is occupied?), still being so transparent that the players understand the inter-dependencies between their decision and the impact this have in the game? In addition to the knowledge about potential collaboration benefits, game solutions would need to incorporate strategic (and operative) decisions and their impact on the benefits of shared resources. Furthermore, it is important for an awareness raising game, that the player experience the boundaries being able to discover that these change in different environment. This requires that multi-criteria decision making processes in highly dynamic systems can be simplified in different levels and be adapted to be applied in different scenarios/settings. This again however requires a high degree of field specific knowledge and a flexible simulation model.

However, these requirements would increase the complexity of games which often may contradict the learning outcome because it may undermine the transmission of the learning objectives by causing confusion. The players may not have the ability anymore, to comprehend their actions and decisions and to reflect them in front of the game results. In order to avioid this and to take the indivdual learning and awareness raising need into account, we use a concept based on scaffolding principle, In a first step we intend to realise a prototype by using a game engine with an authoring tool allowing constructing several scenarios focussing on different aspects and with different levels (both related to complexity and prior need of knowledge). This will require use of learning analytics in order to monitor and trace the gained skills and also for giving the players and the system feedback.

\section{$5 \quad$ Conclusion}

Manufacturing has become a complex process resulting in long brittle supply chains with considerable contributions to the global resource demand and its environmental impact. Materials in short supply and customer requirements trigger market 
stakeholders to reduce the waste of resources and to be more sustainable. Therefore, the ability to share resources, innovate and to implement emergent ICT becomes more important for the competitiveness and sustainability of businesses and companies. Sharing resources puts high standards on trust, gain-sharing, the use of ICT etc. Furthermore, although well known in supply chain management, the logistics sector is struggling to find approaches to collaborate and to share.

Among the identified barriers trust, the management of big data, interoperability issues and the costs of integration seems to be of high importance, but also the lack of understanding of the concept and its advantages contributes to the low penetration rate. This paper looked at the use of SG as a tool for increasing this awareness, and several games that cover some of the aspects and that could be used for overcoming the barrier were identified. This analysis of existing supply chain games revealed their potential but also remaining weaknesses and gaps, both related to the lack of accurate simulation models, as well as suitable ways of balance the reality of the real world with the simplification necessary for awareness raising of complex systems. Here, more research has to be carried out. New games for the discussed purpose would have gone ahead profound research to balance complexity and learning objectives. This research is complemented by the development of advanced serious game (engines), able to handle more indicators and providing substantial feedback and analysis of the game progress. Improved learning analytics will help to develop and evaluate such advanced environments.

Acknowledgements. The research reported in this paper has been partially supported by the European Union, particularly through the projects: GaLA: The European Network of Excellence on Serious Games (FP7-ICT-2009.4.2-258169) www.galanoe.eu and LOGINN (GA 314338).

\section{References}

1. D’Aveni, R. A., Dagnino, G. B., \& Smith, K. G. (2010). The age of temporary competitive advantage. Strategic Management Journal, 31(13), 1371-1385

2. Reichwald, R., \& Piller, F. (2009). Interaktive Wertschöpfung. Wiesbaden: Gabler Verlag.

3. WorldEconomicForum. (2009). Supply Chain Decarbonization: The Role of Logistics and Transport in Reducing Supply Chain Carbon Emissions. Geneva.

4. Cassandra 2012 Cassandra project (2012), Compendium, Download, August 2012, www.cassandra-project.eu

5. DHL 2009 Deutsche Post AG (2009) "Delivering Tomorrow, Customer Needs in 2020 and Beyond - A Global Delphi Study”, Deutsche Post AG, June 2009.

6. Autry, C.W.; L. Michelle Bobbitt, (2008) "Supply chain security orientation: conceptual development and a proposed framework", International Journal of Logistics Management, The, Vol. 19 Iss: 1, pp.42 - 64

7. Ackermann 2011 Ackermann, H. (2011) Mitfahrzentrale für Frachtgüter. Fraunhofer ITWM. Retreived 3rd November, 2011, http://www.itwm.fraunhofer.de/presse-undpublikationen/pressearchiv/pressearchiv-2011/15052011-mitfahrzentrale-fuerfrachtgueter.html

8. Simchi-Levi, D., Peruvankal, J. P., Mulani, N., Read, B., \& Ferreira, J. (2011). Is It Time to Rethink Your Manufacturing Stratgy. MIT Sloan Management Review, 21(December). 
9. WorldTradeOrganization. (2013). International Trade Statistics 2013. Retrieved from http://www.wto.org/english/res_e/statis_e/its2013_e/its2013_e.pdf

10. Minh 2005 Min, S.; Roath, A. S.; Daugherty, P.J.; Genchev, S.E.; Chen, H. and Arndt, A.D.: SC collaboration: what's happening?, The International Journal of Logistics Management, Vol. 16, No. 2, 2005, pp.237-256

11. Jagdev Thoben, 2001 Jagdev, H. S., Thoben, K. -D. (2001), Production Planning \& Control - Anatomy of enterprise collaborations, Volume 12, Issue 5, pp. 437 - 45

12. Braziotis 2011 Braziotis, C. and Tannock, J. (2011), "Building the extended enterprise: key collaboration factors", The International Journal of Logistics Management, Vol. 22 No. 3, pp. 349-372

13. Hesmer, A., Hribernik, K.; Baalsrud Hauge, J.; Thoben, K-D.(2011). Supporting the ideation processes by a collaborative online based toolset. International journal of technology management 55(3/4): 218-225

14. Van Oosterhout M. P. A. et al (2007), Visibility Platforms for Enhancing Supply Chain Security: a Case Study in the Port of Rotterdam. The International Symposium on Maritime Safety, Security and Enviromental Protection, 2007 Athens, Greece

15. Lee, S., Park, G., Yoon, B., \& Park, J. (2010). Open innovation in SMEs: An intermediated network model. Research Policy, 39(2), 290-300.

16. Madrid-Guijarro, A., Garcia, D., \& Van Auken, H. (2009). Barriers to innovation among Spanish manufacturing SMEs. Journal of Small Business Management, 47(4), 465-488.

17. Alter, S. (2012). Metamodel for Service Analysis and Design Based on an Operational View of Service and Service Systems. Service Science, 4(3), 218-235.

18. Fawcett, S. E. and Waller, M.A. (2012): Mitigating the Myopia of Dominant Logics: On Differential Performance and Strategic Supply Chain Research. In: Journal of Business Logistics, 33(3), pp. 173-180

19. Baalsrud Hauge, J., Bellotti, F., Nadolski, R., Kickmeier-Rust, M. D., Berta, R., Carvalho, M. (2013). Deploying serious games for management in higher education: Lessons learned and good practices. In P. Escudeiro and C. Vaz de Carvalho (Eds.), Proc. 7th European Conf. on Games based Learning (pp. 225-234), Oct. 2-3, 2013, Porto, Portugal

20. Campbell, A. , Gontzel, J, Savelsbergh, M.(1999)Experiences with the use of supply chain software in education, Production and Operation management, 9(1), 66-80

21. Lewis, MA, Maylor, HR. (2007) Game playing and operations management education, Int. J. Production Economics, 105 (2007) pp134-149.

22. Anderson, S., et al. (2005). Urban logistics - how can it meet policy makers' sustainability objectives? Journal of Transport Geography 13(1): 71-81

23. Forrester, J. W. (1958). Industrial Dynamics. A major breakthrough for decision makers. Harvard Business Review, 36(4), 37-66.

24. Macdonald, J. R., Frommer, I. D., \& Karaesmen, I. Z. (2013). Decision making in the beer game and supply chain performance. Operations Management Research, 6(3-4), 119-126.

25. Zhou, L., Xie, Y., Wild, N., \& Hunt, C. (2008). Learning and practising supply chain management strategies from a business simulation game: a comprehensive supply chain simulation. In Proc. of IEEE Simulation Conf., 2008. WSC 2008. pp. 2534-2542.

26. Corriere, J. D. (2003). Shortfall: An Educational Game on Environmental Issues in Supply Chain Management. M.S. Thesis. Mechanical \& Industrial Engineering. Northeastern University. Boston MA

27. Azadegan, A., Riedel, J.C.K.H., Baalsrud Hauge, J. (2012) Serious games adoption in corporate training. Lecture Notes in Computer Science including subseries Lecture Notes in Artificial Intelligence and Lecture Notes in Bioinformatics 7528 LNCS, 74-85

28. Gala NoE (2013): D3.3 Serious Games Application Fields report. 